\title{
Patient Satisfaction with Hospital Health Care Services: Outpatient Settings of Combined Military Hospital Bogra
}

\author{
Munir AKMM ${ }^{1}$, Halim AKMY ${ }^{2}$
}

\begin{abstract}
Introduction: In many developing countries, accreditation programs, which have been implemented as a regulatory tool to ensure quality of service and efficient use of resources. To improve the quality of services, health organizations use patient satisfaction survey to evaluate their processes delivered. The care in the Out Patient Department (OPD) indicates the quality of services of any hospital. Combined Military Hospital $(\mathrm{CMH})$ Bogra, is the largest tertiary level military hospital in North Bengal.
\end{abstract}

Objective: To assess the satisfaction levels of patients' in $\mathrm{CMH}$ Bogra related to health care services.

Materials and Methods: A cross sectional study was carried out among 367 patients attending outpatient department of $\mathrm{CMH}$ Bogra. The patients were selected randomly from out patient department. The study was conducted from 01 May 2015 to 31 October 2015. All patients were interviewed using pre-structured questionnaire, which included various variables related to patient satisfaction.

Results: A total number of 367 respondents were interviewed. Majority (48.2\%) of the respondents were from the age category of 26-35 years. Maximum attending population consisted of Army personnel. Overall satisfaction level of patients on hospital services was good. Requirement of separate waiting room for the JCO's and training of the hospital staffs on behaviour with the patients were found important.

Conclusion: Patient satisfaction surveys have evolved as a powerful management and marketing tool. It is being widely used by various hospitals to capture the "Voice of the Consumer". Among the respondents, $95 \%$ of expressed overall satisfaction. This bears a testimony to the efforts of the hospital management towards improvement of services.
Key-words: Health Care Services, Patient Satisfaction, Combined Military Hospital.

\section{Introduction}

Measuring the quality of intangible service products has become a great challenge in health sector. Patient's satisfaction is a useful measure to provide an indicator of quality in health care services. It is a powerful management tool to capture the voice of the consumer. It is also an important tool to determine the success of health care facility. Therefore research on patient satisfaction is important to improve the quality of health service ${ }^{1}$.

Outpatient department (OPD) is the first point of contact with the patients and serves as the shop window to any health care services ${ }^{2}$. The care in the OPD indicates the quality of services of any hospital and it is reflected by patient's satisfaction with the services being provided.

Bangladesh Armed Forces consists of a diverse population of young healthy Bangladeshi soldiers. Their dependents, parents, in laws, civilians who are paid from defense budget and also the retired personnel are availing medical facilities from $\mathrm{CMH}$. The population has diverse socioeconomic status based on their social, cultural and educational background as well as the prevailing rank structure.

$\mathrm{CMH}$ Bogra is the largest tertiary level military hospital in North Bengal. The referral cases come to this hospital from five peripheral military hospitals. The catchment population of this hospital is nearly $4,00,000$. Everyday more than 600 patients are coming for OPD services. This hospital is in the roadside of the Dhaka-Rangpur highway. As a result every day a good number of emergency patients are being received in Emergency and Casualty Department.

1. Lt Col AKM Mashiul Munir, SUP, MBBS, MPH (Hospital Management), Assistant Military Secretary, Army Headquarters, Dhaka 2. Dr AKM Yunus Halim, MBBS, MPhil, RPSGT (USA), RST (USA), PhD, Vice Principal and Associate Professor of Biochemistry, Army Medical College, Bogra. 
Hence study on patient satisfaction related to different parameters of quality health care would reflect the complete picture of all $\mathrm{CMHs}$ of Bangladesh Army.

The present study undertook a satisfaction survey of personnel of Bangladesh Armed Forces and their dependents visiting OPD of $\mathrm{CMH}$ Bogra. The aim of the study was to identify the key factors that affect patient satisfaction regarding health care services of $\mathrm{CMH}$ Bogra.

\section{Materials and Methods}

A cross sectional study was carried out among 367 patients attending outpatient department of $\mathrm{CMH}$ Bogra. Everyday 6-10 patients were randomly selected and were interviewed by the researcher. For discussion purpose excellent was considered as highly satisfied, good as satisfied and bad as dissatisfied. The study was conducted from 01 May 2015 to 31 October 2015.

All the patients were interviewed using pre-structured questionnaire, which includes:

1. Socio-demographic characteristics of the respondents

2. Waiting time, seating arrangements and cleanliness

3. Services provided by the doctor and other Para-medical staffs and their behavior with patients

4. Clinical care

5. Approach to various department, dispensary and laboratory

6. Privacy of patients during physical examination by doctors

\section{Availability of medicine}

8. Over all remark and any suggestions

9. The questions included in this study were replied in choices like excellent/good/bad/not applicable. In case of paediatrics (less than 12 years) patients, the opinion of caregiver or parents was taken. Consent was taken verbally. Informed verbal consent was obtained before data collection. The purpose and method of the study was explained. All the respondents were assured of complete anonymity and confidentiality. The protocol was submitted to the Ethical Committee of Directorate General Medical Services and necessary permission was obtained. At the same time approval to conduct the study was taken from General Officer Commanding (GOC) of 11 Infantry Division, Bogra Cantonment.

\section{Results}

This study consists of total 367 respondents who came from different districts of Rajshahi and Rangpur Division as well as in and around of Bogra cantonment. Among these 367 patients, male-female ratio was 11:14. Literacy status of the patients showed that all the patients were literate and majority (89.1\%) were between SSC and HSC whereas $5 \%$ were below SSC and another 5\% were graduates or above. Majority of the respondents $(48.2 \%)$ were from the age category of 26-35 years.

Table-I: Distribution of respondents regarding their socio-demographic characteristics $(n=367)$

\begin{tabular}{|c|l|c|c|}
\hline \multicolumn{2}{|c|}{ Characteristics } & $\begin{array}{c}\text { Number of } \\
\text { Patients }\end{array}$ & $\%$ \\
\hline \multirow{4}{*}{ Age } & $18-25$ years & 84 & 23 \\
\cline { 2 - 4 } & 26-35 years & 177 & 48 \\
\cline { 2 - 4 } & 36-50 years & 98 & 27 \\
\cline { 2 - 4 } & Above 50 years & 8 & 2 \\
\hline \multirow{3}{*}{$\begin{array}{c}\text { Educational } \\
\text { Status }\end{array}$} & Below SSC & 20 & 5 \\
\cline { 2 - 4 } & SSC passed & 200 & 55 \\
\cline { 2 - 4 } & HSC passed & 127 & 35 \\
\cline { 2 - 4 } Gender & Bachelor degree and above & 20 & 5 \\
\hline \multirow{2}{*}{ Gende } & 161 & 44 \\
\cline { 2 - 4 } & Female & 206 & 56 \\
\hline
\end{tabular}

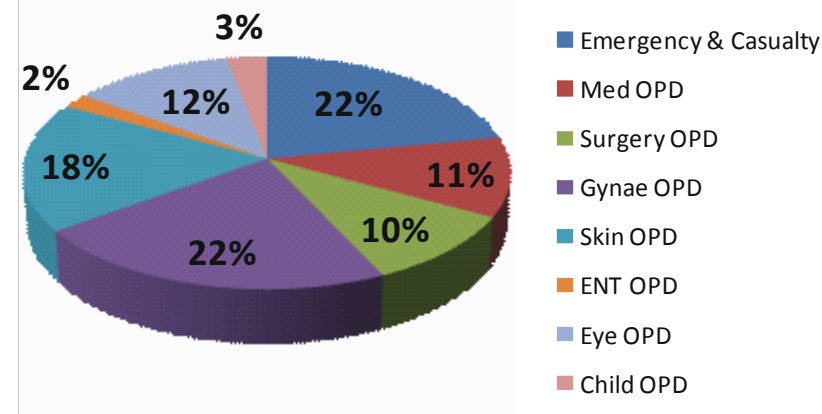

Fig-1: Distribution of respondents based on concern departments $(n=367)$

Details department wise distribution of responses is shown in figure-1. Data in table-Il revealed that the overall satisfaction level of patients on hospital services was good. Most of the respondents expressed highly satisfaction (43\%) to satisfaction (53\%) about the behavior of the paramedics and staffs. In this study, $34 \%$ of the respondents were highly satisfied with the waiting arrangement whereas $56 \%$ were satisfied with the waiting time. But $9 \%$ of the study 
population showed dissatisfaction. Out of 367 respondents, 47 were Junior Commissioned Officer (JCO) and their dependents. Among them 14\% were dissatisfied on waiting time. Dispensary is the usual exit point, where patients arrive after OPD consultation, collect medicine and depart. It is also one of the bottlenecks in the normal flow of hospital. In this study $9 \%$ of female respondents expressed dissatisfaction in comparison to $7 \%$ of the male respondents. Of the total $34 \%$ of the respondents expressed their high level of satisfaction on getting the medicine as per the prescription whereas $10 \%$ of the respondents were dissatisfied (Table-II).

Table-II: Distribution of responses from the respondents on hospital staffs and availability of service $(n=367)$

\begin{tabular}{|l|l|c|}
\hline \multicolumn{2}{|c|}{ Hospital Staffs and Availability of Service } & Percentage of Patients \\
\hline \multirow{3}{*}{ Behaviour of medical staffs } & Excellent & 43 \\
\cline { 2 - 3 } & Good & 53 \\
\cline { 2 - 3 } & Bad & 4 \\
\hline \multirow{3}{*}{ Quality of outdoor waiting arrangement } & Excellent & 34 \\
\cline { 2 - 3 } & Good & 56 \\
\cline { 2 - 3 } & Bad & 10 \\
\hline \multirow{4}{*}{ Waiting time for doctors } & Excellent & 28 \\
\cline { 2 - 3 } & Good & 62 \\
\cline { 2 - 3 } & Bad & 8 \\
\cline { 2 - 3 } & Not-mentioned & 2 \\
\hline \multirow{3}{*}{ Medicine supply system from Dispensary } & Excellent & 32 \\
\cline { 2 - 3 } & Good & 59 \\
\cline { 2 - 3 } & Bad & 3 \\
\hline \multirow{3}{*}{ Experience on availability of medicine as per prescription } & Excellent & 55 \\
\cline { 2 - 3 } & Good & 10 \\
\cline { 2 - 3 } & Bad & 1 \\
\cline { 2 - 3 } & Not-mentioned & 34 \\
\hline
\end{tabular}

Patient's compliance in respect to clinical care (Table-III) was more towards satisfactory side. As it was $49 \%$ for doctors attention towards the patients, $61 \%$ for time given to the patients, $60 \%$ for giving clear idea about disease, medicine and dose. Among the respondents $63 \%$ replied that the privacy maintenance during physical examination was highly satisfactory (Table-III).

Table-III: Distribution of responses from the respondents regarding Clinical Care $(n=367)$

\begin{tabular}{|l|l|c|}
\hline \multicolumn{2}{|c|}{ Clinical Care } & Percentage of Patients \\
\hline \multirow{3}{*}{ Doctors' attention towards patient while taking the history } & Excellent & 48 \\
\cline { 2 - 3 } & Good & 49 \\
\cline { 2 - 3 } & Bad & 3 \\
\hline \multirow{4}{*}{ Examination time given to the patient by the doctors } & Excellent & 35 \\
\cline { 2 - 3 } & Good & 61 \\
\cline { 2 - 3 } & Bad & 3 \\
\cline { 2 - 3 } & Not mentioned & 1 \\
\hline \multirow{3}{*}{ Quality to make the patients clear about his problems by the doctors } & Excellent & 36 \\
\cline { 2 - 3 } & Good & 60 \\
\cline { 2 - 3 } & Bad & 4 \\
\hline \multirow{3}{*}{ Quality in explaining the patients about medicine \& dose by doctors } & Excellent & 34 \\
\cline { 2 - 3 } & Good & 3 \\
\cline { 2 - 3 } & Bad & 34 \\
\hline \multirow{3}{*}{ Quality of privacy maintenance by the doctors during clinical examination } & Excellent & 63 \\
\cline { 2 - 3 } & Good & 2 \\
\cline { 2 - 3 } & Bad & 1 \\
\cline { 2 - 3 } & Not mentioned & \\
\hline
\end{tabular}


Table-IV shows that all the respondents expressed high degree of satisfaction for accessibility to the OPD and its location. Among the respondents $16 \%$ were dissatisfied in respect to cafeteria facility.

Table-IV: Distribution of responses as per the opinon related to hospital utility service $(n=367)$

\begin{tabular}{|l|l|c|}
\hline \multicolumn{2}{|c|}{ Hospital Utility Services } & Percentage of Patients \\
\hline \multirow{3}{*}{ Opinion on overall hospital cleanness } & Excellent & 45 \\
\cline { 2 - 3 } & Good & 53 \\
\cline { 2 - 3 } & Bad & 2 \\
\hline \multirow{3}{*}{ Opinion on accessibility to hospital ward/department } & Excellent & 43 \\
\cline { 2 - 3 } & Good & 52 \\
\cline { 2 - 3 } & Bad & 32 \\
\hline \multirow{4}{*}{ Response on hospital cafeteria facilities for patients' services } & Excellent & 51 \\
\cline { 2 - 3 } & Good & 16 \\
\cline { 2 - 3 } & Bad & 1 \\
\cline { 2 - 3 } & Not mentioned & 38 \\
\hline \multirow{3}{*}{ Response on overall hospital management and helping facilities } & Excellent & 57 \\
\cline { 2 - 3 } & Good & 4 \\
\cline { 2 - 3 } & Bad & 1 \\
\cline { 2 - 3 } & Not mentioned & \\
\hline
\end{tabular}

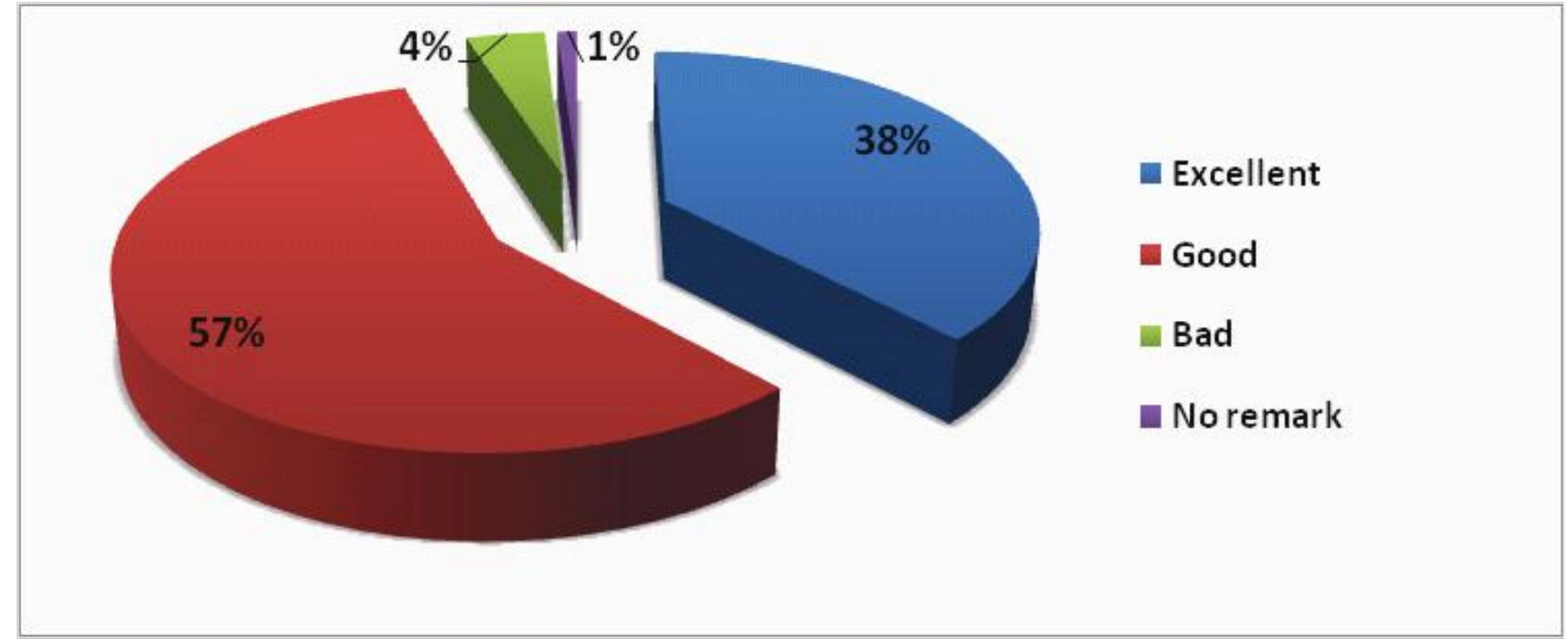

Fig-2: Distribution of satisfaction judgment about overall hospital OPD services

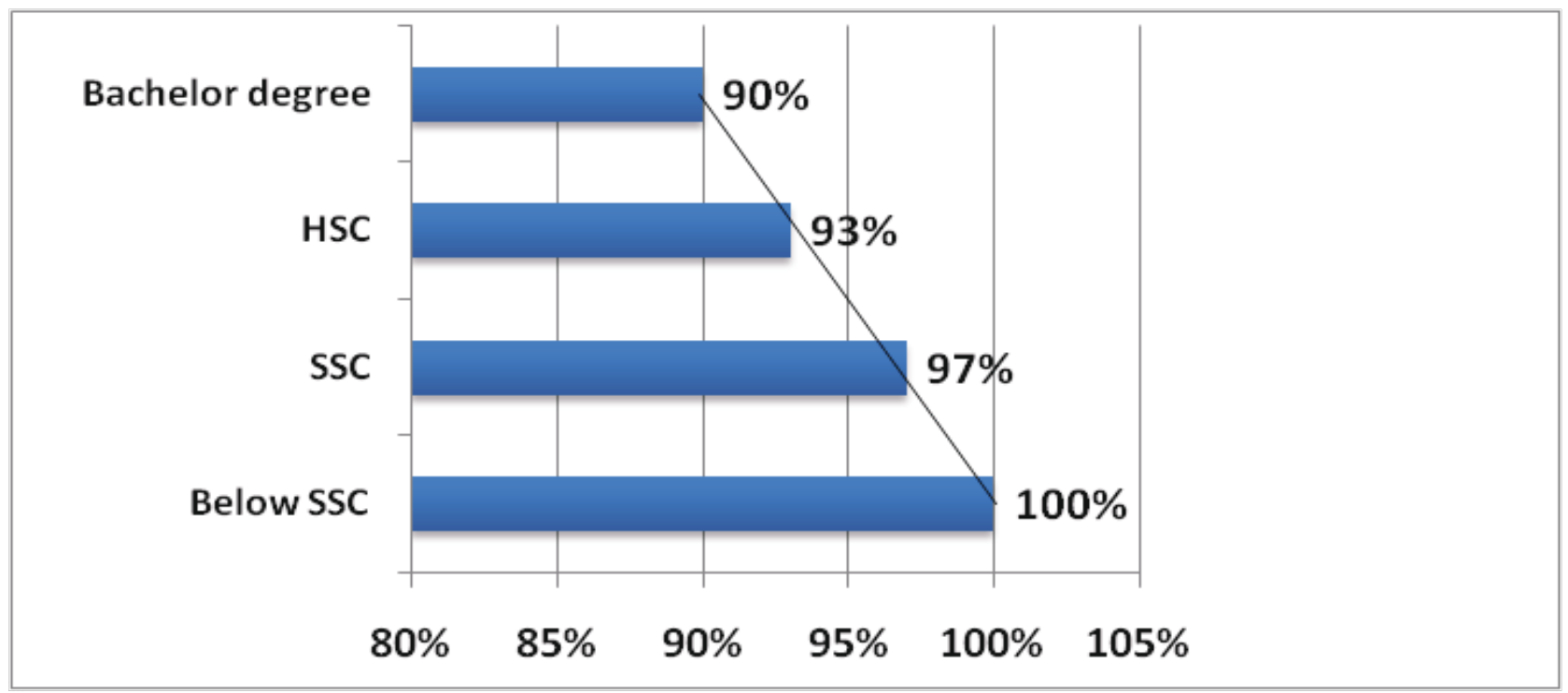

Fig-3: The bar diagrams cross tab shows the relation between education status and level of satisfaction 
Figure-3 shows that patient's satisfaction level was inversely related to education status of the respondents (Chi-square value-17.833, $p<0.05$, df-9). Women were more satisfied (99\%) with OPD services compared to their male counterparts $(92 \%)$. Chi-square test $(p<0.05, \mathrm{df}-3)$ also supported this relation. Level of satisfaction depends upon the services that respondents are receiving. Age of the respondents has no relation to this (Chi-square test was not significant, $p>0.05$ ).

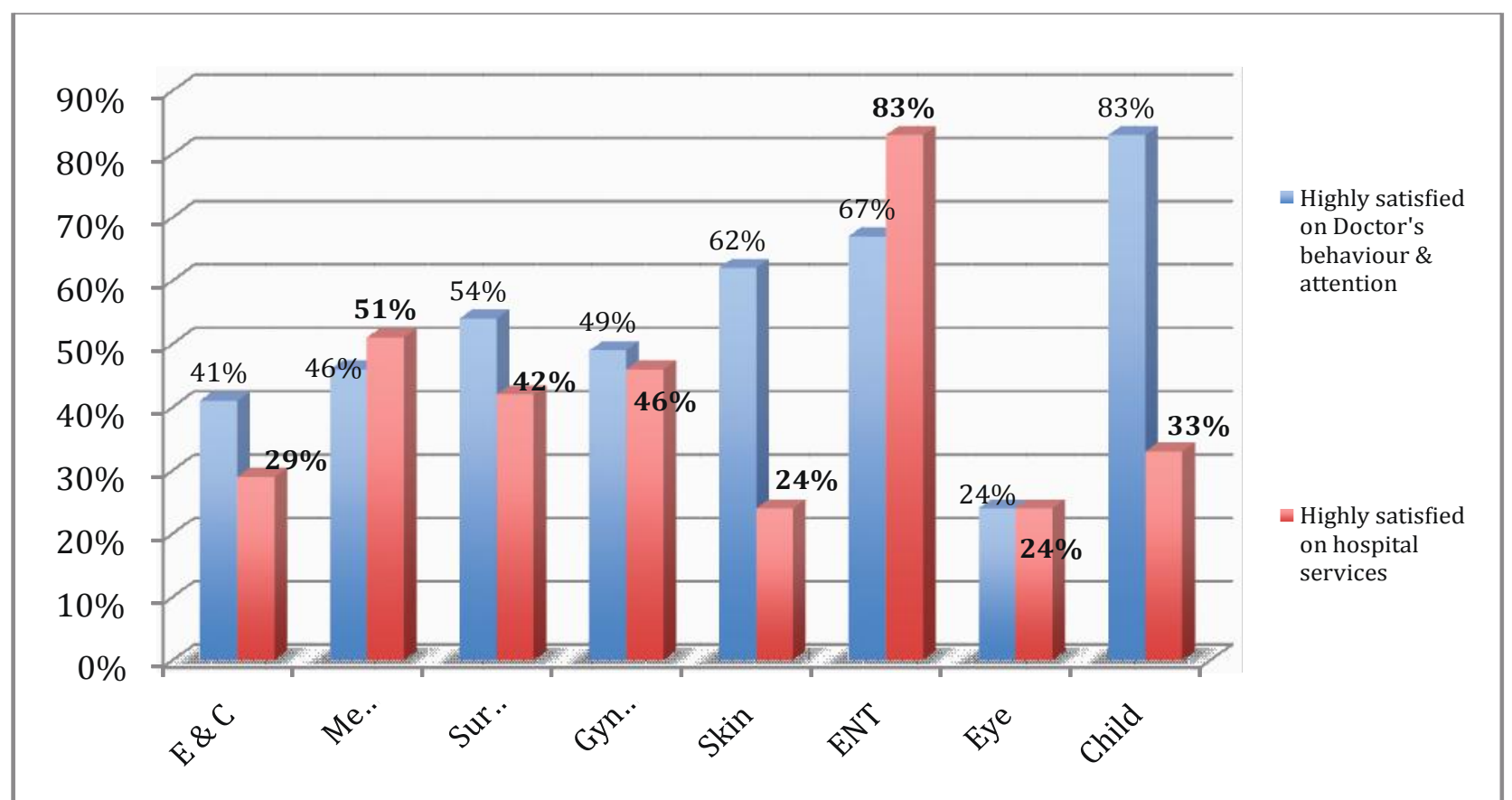

Fig-4: Multiple bar diagram showing the relation with doctor's behaviour and attitude on overall patient's satisfaction on hospital OPD services

Figure-4 shows that the behaviour and attitude of the doctors who work in the OPD reflects the overall patient's satisfaction status. Almost in all the OPD's paramedics and nurses behaviour and attitude reflects the overall patient's satisfaction status (Figure-5).

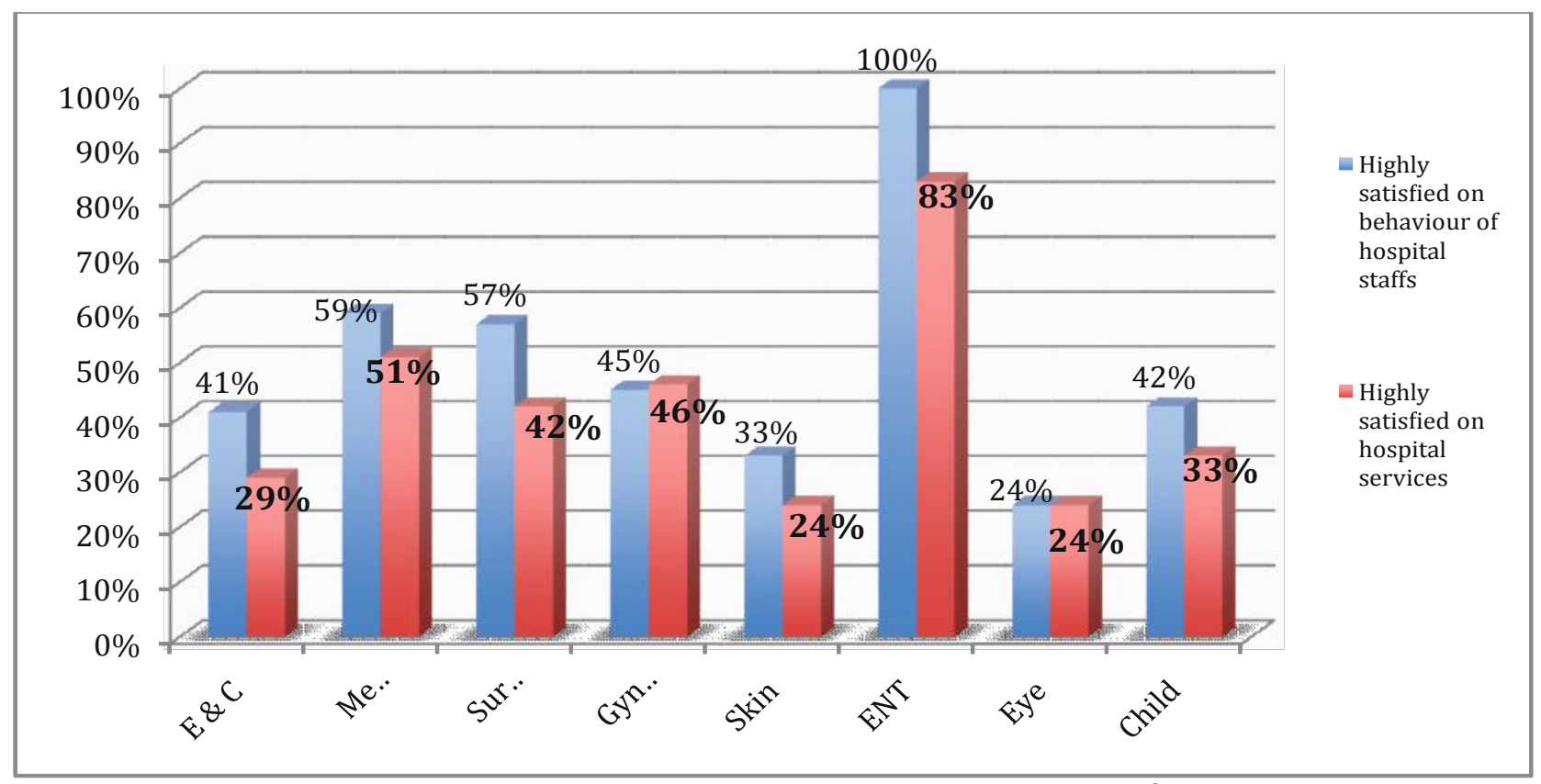

Fig-5: Multiple bar diagram showing the relation with the behaviour and attitude of paramedics and nurses on overall patient's satisfaction on hospital OPD services 


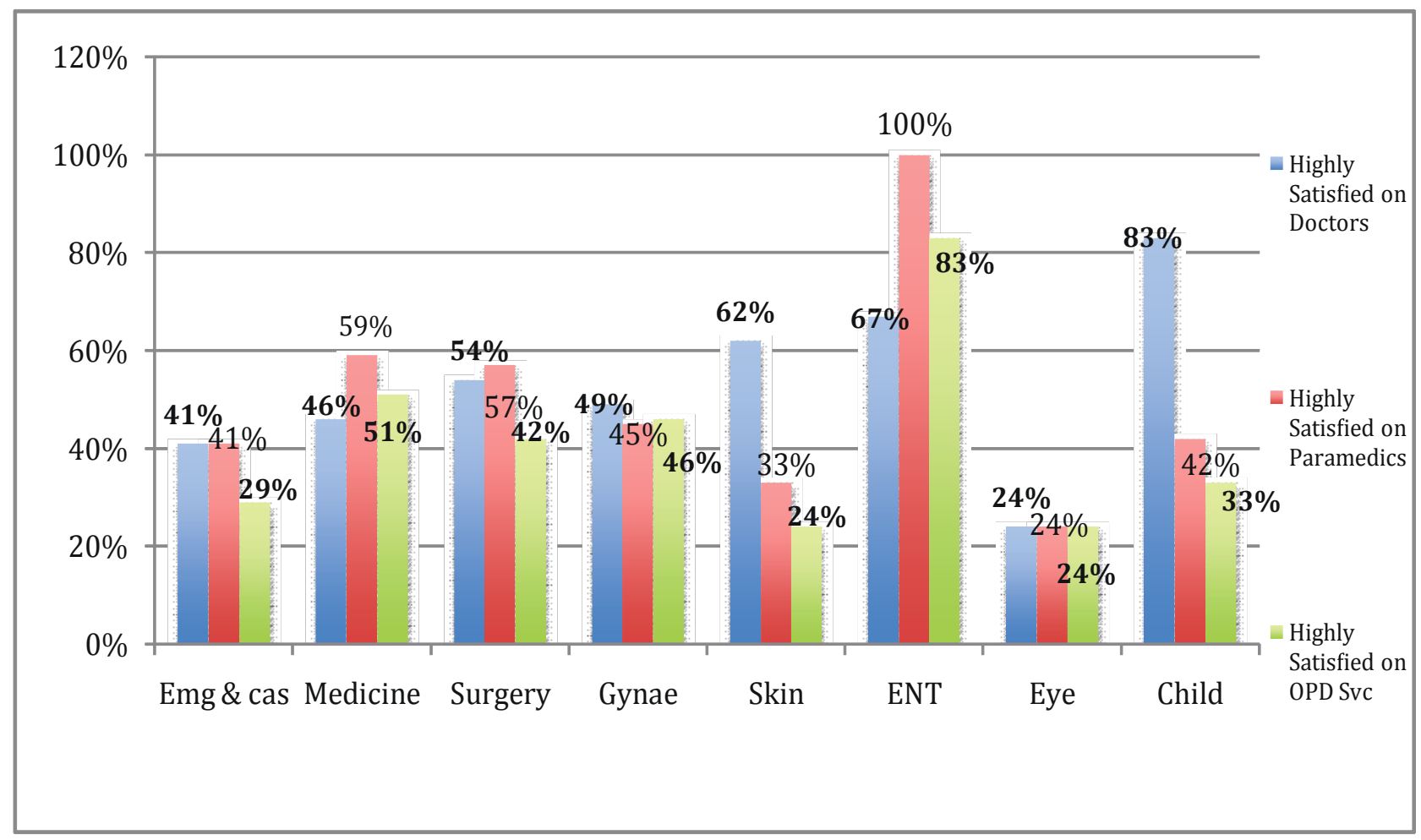

Fig-6: Multiple bar diagram showing the comparative picture of overall patient's satisfaction on hospital OPD services in relation with the behaviour and attitude of doctors, paramedics and nurses

This multiple bar diagram of Figure- 6 is a combination of Figure-4 and 5. The aim is to find out the dependent variable, that is, to what extent patient's satisfaction is dependable on the independent variables - the behavior of doctor's, paramedics and nurses. Figure-7 reflects the clear relation between patient's satisfaction and out door waiting time.

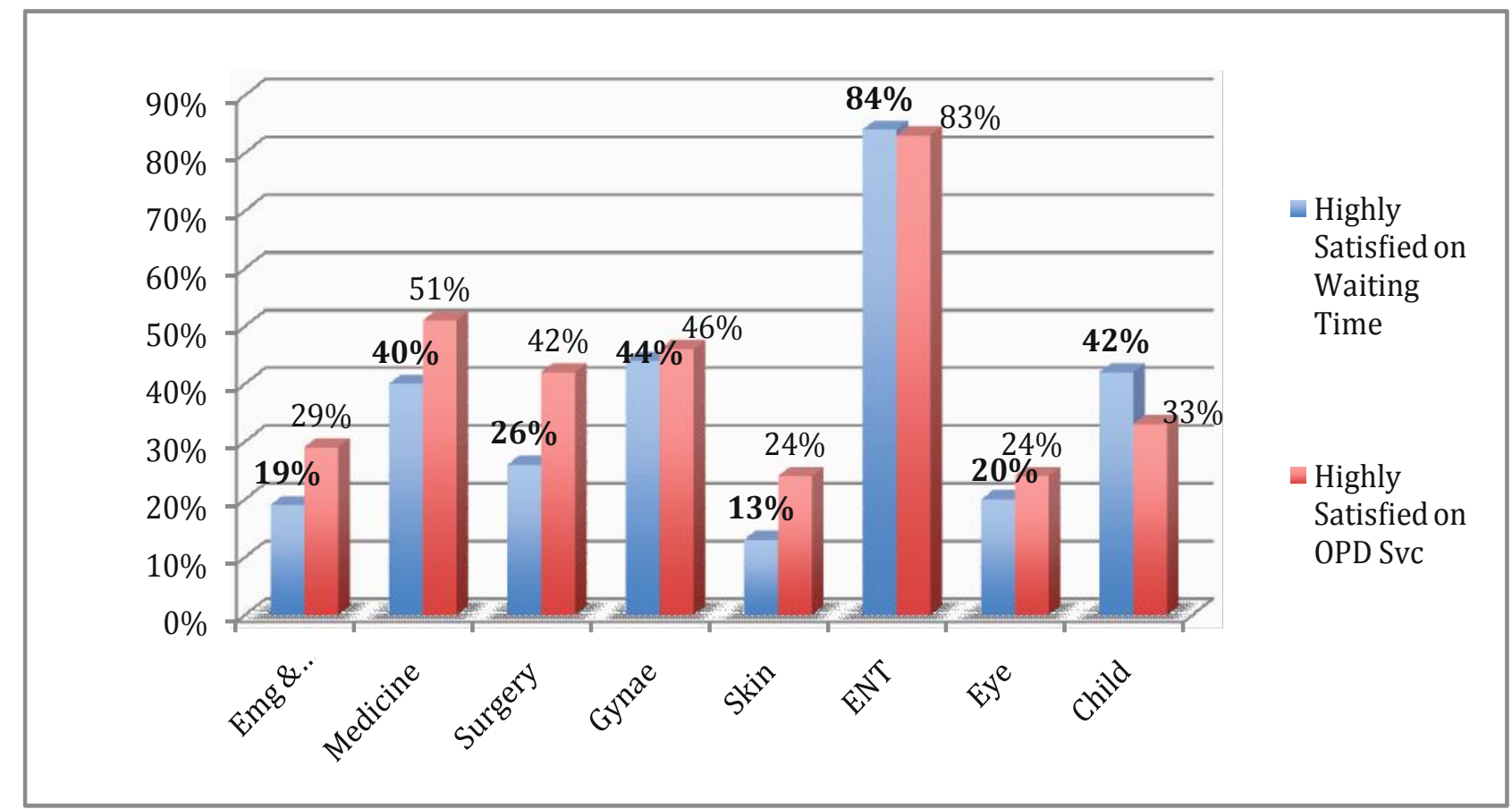

Fig-7: Multiple bar diagram showing the relation with the waiting time and overall patient's satisfaction on hospital OPD services 


\section{Discussion}

Consumer satisfaction is recognized as an important parameter for assessing the quality of health care services. The attitude of providers toward these services is expected to affect treatment outcome and prognosis. Patient satisfaction is a multidimensional concept and a subjective phenomenon that is linked to perceived needs, expectation and experience of care ${ }^{3}$.

When waiting times become inevitable, waiting rooms need to be supplied with television sets, newspaper, magazine and adequate sanitary facilities to reduce the monotony of waiting. Provisions of these amenities are within reach of hospital management. This needs to be addressed with certain amount of urgency to remove sources of dissatisfaction. In this study $10 \%$ of the respondents were dissatisfied. This dissatisfaction was $14 \%$ in case of JCOs. It might be a cause that there were no separate waiting facilities for the JCOs and their dependents. Atahar and Chakravarty conducted a study in Indian Armed Forces. A study conducted by Indian Army revealed that the JCOs were highly dissatisfied ${ }^{2}$. The dissatisfaction level among the JCOs was $60-70 \%$ in Indian Army ${ }^{2}$. In this study 9\% of the respondents were dissatisfied about the medicine collection system from dispensary. The cause of dissimilarity with this study might be that in $\mathrm{CMH}$ Bogra there is separate counter for the JCOs. But this was absent in Indian Army hospital ${ }^{2}$.

In this study $10 \%$ of the patients have shown dissatisfaction on medicine supply as per the prescription. The contributing factors may be as follows: many of the items prescribed were not available in the dispensary; there may be an information gap of supplied medicine list with the doctors; the local purchasing (LP) procedure may be prolonged.

Attributes those are important for doctor-patient relationship are sympathy, good communication and shared responsibility in managing illness of patients. In this study satisfaction level was high regarding doctor's attention towards patients. This result is similar to a study of an Indian hospital ${ }^{4}$ and also to a Nigerian study $^{5}$. Short consultation time with doctors is a common source of patient dissatisfaction. In this study $96 \%$ of the respondents were satisfied in this regard.
This finding is similar to the study findings conducted in an Indian Armed Forces Hospital by Athar and Chakravarty ${ }^{2}$. The satisfaction level was $85.2 \%$ in that hospital. Privacy and confidentiality are basic rights of patients. This also builds trustful and open relationship with doctors. In this study $34 \%$ of the respondents were highly satisfied with the privacy maintenance. To improve the satisfaction level, doctor's attention as well as improvisation of the clinical room may be required.

This study found that patient's satisfaction level was inversely related to the education status of the respondents. This finding is also similar to the findings of Imam Reza Hospital, Tabriz, Iran ${ }^{6}$. It is also similar to the study conducted on 2015 in Malaysia ${ }^{7}$. Women were satisfied $(99 \%)$ with OPD services compared to their male counterparts (92\%). Hence this study is similar to the findings of Dhaka Medical College Hospital $^{8}$ and also with the study of Pakistan ${ }^{9}$.

Level of satisfaction is dependent on the service not with age. Hence this study finding is not similar to the Nigerian study ${ }^{5}$ but supported by the study of Pakistan 9 .

The study shows that the behaviour and attitude of the doctors reflects the overall patient's satisfaction status. This type of comparison was not found in other available studies for matching. But in $\mathrm{CMH}$ Bogra two OPDs namely in Skin and Child, the satisfaction level on doctor's behaviour does not commensurate with over all satisfaction on both the OPDs. Other independent variables like waiting facilities, cleanliness and behavior of paramedic or nurses may be related in this two OPDs.

Polite and courteous behaviour of the hospital staffs is a necessity for hospital OPD services. Training of hospital staffs and in particular the civilian staffs might have positive impact towards higher satisfaction level. Pawar ${ }^{10}$ found $90 \%$ of the respondents remarked that OPD services were satisfactory ${ }^{2,11}$. The finding is similar to the findings of this study at $\mathrm{CMH}$ Bogra.

Almost in all the OPD's paramedics and nurses behaviour and attitude reflects the overall patient's satisfaction status. This type of comparison also was not found in other available studies for matching. 
Other independent variables like waiting facilities, cleanliness and behaviour of doctors may be responsible. Surprisingly unlike the other OPDs of Bogra $\mathrm{CMH}$ patient satisfaction level is very high in ENT OPD. There was no JCO in any of the OPDs except ENT. It might be the cause that the managerial capabilities of the JCO have brought the graph high (Satisfaction on doctor is $67 \%$, on paramedics $100 \%$ and overall is $83 \%$ ).

The multiple bar diagram of figure- 6 reflects, to what extent the patient satisfaction is dependent on behaviour of doctor, nurse and paramedics. Which has been reflected in ENT and Eye OPD of Bogra CMH.

Patient's waiting time is an inevitable but at the same time a vital issue. It restricts in achieving patient satisfaction. This is the major reason for patients complain regarding their experience in OPD. In Bogra $\mathrm{CMH}$ only $9 \%$ attendants were dissatisfied with the time gap between coming to hospital and consultation with the doctor. This dissatisfaction was $32 \%$ at Gujrat in India ${ }^{4}$.

SK Jawahar ${ }^{12}$ found that $50 \%$ of the patients were satisfied with the cleanliness of a super specialty hospital in India. Whereas Krupal Joshi ${ }^{2}$ found in Gujrat that, patients were fully satisfied regarding hospital cleanliness. The study findings in $\mathrm{CMH}$ Bogra are similar to the findings of Krupal Joshi.

\section{Conclusion}

Patient satisfaction surveys have evolved as a powerful management and marketing tool. It is being widely used by various hospitals to capture the "Voice of the Consumer". It also helps to understand the views of the patients in respect of hospital services being provided. Despite certain structural constraints, $95 \%$ of all patients have expressed overall satisfaction judgment with OPD services in Bogra $\mathrm{CMH}$. This bears a testimony to the efforts of the hospital management towards improvement of services. The hospital authority may derive affordable inputs from similar surveys to identify improvement opportunities. Continuous monitoring to assess the degree of sustainable improvement is required. The study suffers from certain limitations, namely recording of waiting time and consultation time. It is recommended that a future study with a larger scope to improve the quality and outcome of such studies.

\section{References}

1. Andaleeb SS, Siddiqui N and Khandakar S. Patient satisfaction with health services in Bangladesh. Health policy and planning (Oxford Journals) 2007; 22(4): 263-73.

2. Bowling A, Rowe G and McKee M. Patients' experiences of their healthcare in relation to their expectations and satisfaction: a population survey. Journal of the Royal Society of Medicine 2013; 106:143-9.

3. Atahar M and Chakravarty A. Patient satisfaction with services of outpatient department. Medical Journal Armed Forces India 2014; 70:237-42.

4. Joshi K, Sochaliya K, Purani S et, al. Patient satisfaction with health care services: A cross sectional study of patients who visit the outpatient department of a civil hospital at Surendranagar, Gujrat IJMSPH 2013; 2(3):659-63.

5. Adamu $\mathrm{H}$ and Oche MO. Patient Satisfaction with Services at a General Outpatient Clinic of a Tertiary Hospital in Nigeria. British Journal of Medicine \& Medical Research 2014; 4(11):2181-2202.

6. Soleimanpour H, Gholipouri C, Salarilak S, et al. Emergency department patient satisfaction survey in Imam Reza Hospital, Tabriz, Iran. International Journal of Emergency Medicine 2011; 4(2):1-7.

7. Ganasegeran K, Perianayagam W, Manaf RA et al. Patient Satisfaction in Malaysia's Busiest Outpatient Medical Care. The Scientific World Journal 2015; 1-6.

8. Islam MZ and Jabbar MA. Patients' Satisfaction of Health Care Services Provided at Out Patient Department Of Dhaka Medical College Hospital. Ibrahim Medical College Journal 2008; 2(2):55-7.

9. Shaikh BT, Mobeen N, Azam SI et al. Using SERVQUAL for assessing and improving patient satisfaction at a rural health facility in Pakistan. Eastern Mediterianean Health Journal 2008; 14(2):447-56.

10.Pawar AA and Mukherji S. A Survey Cum Study On the level of satisfaction with the quality and delivery of healthcare at INHS Sanjivani. J Mar Med Soc 2011; (13): 119-23.

11. Raheem AR, Nawaz A, Fouzia N et al. Patients' Satisfaction and Quality Health Services: An Investigation fromPrivate Hospitals of Karachi. Research Journal of Recent science 2014; 3(7):34-8.

12. Jawahar SK. A Study on Out Patient Satisfaction at a Super Specialty Hospital in India. Internet Journal of Medical Update 2007; 2(2):13-7. 